\title{
EL REFERÉNDUM DEL TLC EN COSTA RICA: SEGUIMIENTO DE LA OPINIÓN PÚBLICA
}

\section{CAFTA REFERENDUM IN COSTA RICA: FOLLOWING PUBLIC OPINION}

\author{
Florisabel Rodríguez* \\ Miguel Gómez Barrantes** \\ Wendy Chacón C.*
}

RESUMEN

Este artículo describe la evolución de la opinión pública, mediante encuestas nacionales telefónicas, durante la campaña sobre el Referéndum acerca del Tratado de Libre Comercio (TLC) entre Costa Rica, Centroamérica, República Dominicana y Estados Unidos. Se seleccionaron indicadores sobre nivel de información y posibles efectos sobre la persona entrevistada, el país, el Estado y los grupos vulnerables.

PALABRAS CLAVE: COSTA RICA * REFERÉNDUM * TLC $*$ ENCUESTAS ELECTORALES PARA REFERÉNDUM $*$ PEQUEÑOS AGRICULTORES $*$ PEQUEÑOS EMPRESARIOS * EMPLEO * ESTADO SOLIDARIO $*$ SOBERANÍA

\section{ABSTRACT}

This paper describes the evolution of public opinion, during the Referendum campaign over CAFTA. The data is based on telephone national surveys and includes the level of information, possible effects on the person interviewed, on the country, on its welfare State and on poor and vulnerable groups.

KEY WORDS: COSTA RICA $*$ REFERENDUM $*$ CAFTA $*$ REFERENDUM CAMPAIGN SURVEYS $*$ SMALL FARMERS $*$ SMALL BUSINESS $*$ EMPLOYMENT * WELFARE $*$ SOVEREIGNTY

Centro de Investigación Social PROCESOS florisabel@procesos.org

** $\quad$ Centro de Investigación Social PROcESOS migoba@racsa.co.cr
*** Centro de Investigación Social PROCESOS wchacon@procesos.org 
PARTE A: Introducción

ÍNDICE

PARTE B: Las tres fases 51

Fase inicial: la indecisión

Segunda fase: tendencia a la baja del apoyo al TLC y al SÍ

Tercera fase: la volatilidad del último tramo de la campaña y el empate final

PARTE C: Evolución de indicadores de principales temas en disputa

Proporción que se siente razonablemente informada sobre el TLC

Los posibles efectos sobre el país

Los posibles efectos negativos del TLC sobre el Estado solidario

Los posibles efectos del TLC sobre los grupos percibidos como vulnerables

Los posibles efectos del TLC sobre la persona entrevistada

PARTE D: Comentarios finales

Bibliografía

Cuadro Nombre

\section{ÍNDICE DE CUADROS}

A1 Descripción general de las encuestas sobre el TLC durante el 2007. PROCESOS Investigación y Asesoría S.A.

B1 Opinión general sobre el TLC. Marzo - Octubre 2007

B2 Intención de voto en el Referéndum sobre el TLC. Marzo - Octubre 2007

B3 Intención de voto en el Referéndum, por día durante las últimas tres semanas (suavizada con promedios móviles de 3 días)

C1 Nivel de información sobre el TLC. Mayo - Octubre 2007

C2 Efectos económicos y sociales del TLC sobre Costa Rica. Mayo - Octubre 2007

C3 Opinión sobre cuál será el país ganador con el TLC entre Estados Unidos (EU) y Costa Rica (CR). Mayo - Octubre 2007

C4 Efectos del TLC sobre la soberanía de Costa Rica. Mayo - Octubre 2007

C5 Efectos del TLC sobre el Estado Solidario. Mayo - Octubre 2007

C6 Efectos del TLC sobre los grupos percibidos como vulnerables. Mayo - Octubre 2007

C7 Efectos del TLC sobre la persona entrevistada y su familia. Mayo - Octubre 2007

Gráfico Nombre

\section{ÍNDICE DE GRÁFICOS}

1 Evolución de la opinión general sobre el TLC. Marzo - Octubre 2007

2 Evolución de la intención de voto en el Referéndum. Marzo - Octubre 2007

Evolución de la intención de voto en el Referéndum. Índice de diferencia \%Sí - \%NO. Mayo - Octubre 2007

4 Evolución de la intención de voto de los posibles votantes en las últimas tres semanas de la campaña del Referéndum. Datos diarios suavizados con promedios de tres días.

5 Evolución del índice de intención de voto de los posibles votantes (últimas tres semanas de la campaña del Referéndum)

Evolución del índice del nivel de información sobre el TLC. Mayo - Octubre 2007.

7 Evolución del índice de los efectos económicos y sociales del TLC sobre Costa Rica. Mayo - Octubre $2007 \quad 60$

8 Evolución del índice del país ganador con el TLC

9 Evolución del índice de los efectos del TLC sobre la soberanía de Costa Rica. Mayo - Octubre 2007

10 Evolución del índice de los efectos del TLC sobre el Estado solidario. Mayo - Octubre 2007

11 Evolución del índice de los efectos del TLC sobre los pequeños empresarios, pequeños agricultores y los pobres. Mayo - Octubre 2007

12 Evolución del índice de los efectos del TLC sobre los empleados públicos y los educadores. Mayo - Octubre 2007

13 Evolución del índice de los efectos del TLC sobre la persona o su familia. Mayo - Octubre 2007 


\section{PARTE A: INTRODUCCIÓN ${ }^{1}$}

El objetivo del presente artículo es describir la evolución de una serie de indicadores en la opinión pública durante la campaña sobre el primer Referéndum acerca del Tratado de Libre Comercio (TLC) entre Costa Rica, Centroamérica, República Dominicana ${ }^{1}$ y Estados Unidos (Sobrado, 2007; Pecóu Daley, 2007).

Este trabajo de seguimiento de la opinión pública se realizó a través de encuestas cuyo trabajo de campo se realizó durante la campaña del Referéndum. Dichas encuestas se realizaron periódicamente, primero mensuales, luego quincenales y al final, diarias, con una muestra representativa de la población nacional, habitante en viviendas con teléfono de línea fija. El siguiente cuadro muestra la identificación de cada encuesta, las fechas de recolección, el tamaño de la muestra y el margen de error de cada estudio.
La recolección de información se extiende desde mayo del 2007, cuando el Tribunal Supremo de Elecciones (TSE) anuncia que habrá Referéndum sobre el TLC, hasta el 5 de octubre del mismo año. La campaña termina oficialmente el 4 de octubre y la votación se hace el 7 de octubre.

La concurrencia a esta votación es del 59,24\% del padrón electoral. El sí al Tratado de Libre Comercio obtiene el $51,2 \%$ del total de los votos recibidos y el No el 48,1\% del mismo total (Tribunal Supremo de Elecciones, 2007). Así, por diferencia de tres puntos porcentuales el TLC se convierte en ley de la República.

Todo este período, estuvo marcado por campañas publicitarias y comunicaciones de diversa índole en los medios de comunicación masiva, la Internet, el teléfono y el boca a boca. Se dieron marchas, debates, reuniones, muchas noticias, entrevistas y eventos mediáticos ${ }^{2}$.

CUADRO A1

DESCRIPCIÓN GENERAL DE LAS ENCUESTAS SOBRE EL TLC DURANTE EL 2007 -PROCESOS INVESTIGACIÓN Y ASESORÍA SA.-

\begin{tabular}{lccc}
\hline $\begin{array}{l}\text { IDENTIFICACIÓN DE LA } \\
\text { ENCUESTA }\end{array}$ & $\begin{array}{c}\text { PERÍODO DE } \\
\text { RECOLECCIÓN }\end{array}$ & $\begin{array}{c}\text { TAMAÑO DE } \\
\text { MUESTRA }\end{array}$ & MARGEN DE ERROR \\
\hline Marzo & $15-23$ & 619 & 4,0 \\
Mayo & $2-13$ & 632 & 4,0 \\
Junio & $16-23$ & 633 & 4,0 \\
Agosto/ 1 & $1-10$ & 704 & 3,8 \\
Agosto/ 2 & $21-28$ & 705 & 3,8 \\
Setiembre/ 1 & $1-8$ & 726 & 3,7 \\
Setiembre/2 & $17-24$ & 710 & 3,7 \\
Setiembre/3 & $26-29$ & 373 & 6,0 \\
Octubre & $1-5$ & 493 & 4,5 \\
\hline
\end{tabular}

Fuente: PROCESOS, Encuestas TLC marzo-octubre, 2007.

1 Agradecemos a Marcela Piedra su colaboración para la elaboración de este artículo. Así mismo, los comentarios de las personas investigadoras del Instituto de Investigaciones Sociales y de la persona lectora para la Revista. con Estados Unidos y los países de Centroamérica, la que se concretó en agosto del 2004.

3 Se vivió una intensa y polémica campaña del sí y otra del NO. El 23 de junio inicia formalmente la campaña del NO en conferencia de prensa en la Conferencia Episcopal, acompañada por una intensa campaña electrónica y boca a boca. La campaña en medios de comunicación del sí inicia 15 de agosto con el tema de los corazones, que no gustó a la población. En los últimos 12 días de campaña se dieron anuncios de índole más informativa por parte del Sí. El análisis de estas intensas y polarizadas campañas de comunicación sobre el TLC, es material para otro artículo. 


\section{PARTE B: LAS TRES FASES}

Si se observan las opiniones expresadas sobre la intención de voto para el Referéndum y sobre la opinión sobre el TLC a lo largo del período (marzo-octubre, 2007), se pueden distinguir tres fases de distinta duración:

$\diamond$ primero, una fase inicial de indecisión

$\diamond$ segundo, la fase dominada por la tendencia a la baja de la opinión de que "el TLC es bueno" y la pérdida de apoyo hacia el sí

$\diamond$ tercero, la fase de alta volatilidad y empate final.

En las mediciones de marzo, mayo, junio, agosto, setiembre y octubre se repitieron dos preguntas sobre la intención de voto en el Referéndum y acerca de la opinión sobre TLC: $\diamond$ Si va a votar, ¿votará Sí al TLC o NO al TLC?

$\diamond$ ¿Para Costa Rica el TLC es muy bueno, bueno, malo o muy malo?

Adicionalmente en el voto se utilizó otra pregunta para medir los votantes probables:

$\diamond \quad ¿ E s$ seguro, muy seguro, poco seguro o nada seguro que vote en el Referéndum?

A continuación se presenta el Cuadro B1 correspondiente a la serie de la opinión general sobre si el TLC es bueno o malo para el país.

Las tres fases se pueden ob-servar aún mejor en el Gráfico 1, que traza la evolución de la opinión sobre el TLC.

CUADRO B1

OPINIÓN GENERAL SOBRE EL TLC MARZO-OCTUBRE 2007

\begin{tabular}{lccccccccc}
\hline & \multicolumn{3}{c}{ I } & \multicolumn{3}{c}{ II } & \multicolumn{3}{c}{ III } \\
\cline { 2 - 9 } TLC es ... & Mar-07 & May-07 & Jun-07 & Ag-07/1 & Ag-07/2 & Set-07/1 & Set-07/2 & Set-07/3 & Oct-07 \\
\hline Bueno & 52,8 & 49,6 & 52,2 & 51,1 & 48,0 & 46,9 & 46,7 & 41,4 & 41,0 \\
Indeciso* & 18,7 & 24,8 & 18,5 & 20,6 & 21,5 & 23,8 & 19,8 & 16,0 & 24,7 \\
Malo & 28,4 & 25,7 & 29,3 & 28,3 & 30,5 & 29,3 & 33,4 & 42,6 & 34,3 \\
Total & 100,0 & 100,0 & 100,0 & 100,0 & 100,0 & 100,0 & 100,0 & 100,0 & 100,0 \\
\hline ÍNDICE** & $+24,4$ & $+23,9$ & $+23,0$ & $+22,8$ & $+17,5$ & $+17,6$ & $+13,3$ & $-1,2$ & $+6,8$
\end{tabular}

*Incluye la opinión regular y los que no saben o no responden. ** Índice = \%Bueno - \% Malo.

Fuente: PROCESOS, Encuestas TLC marzo-octubre, 2007.

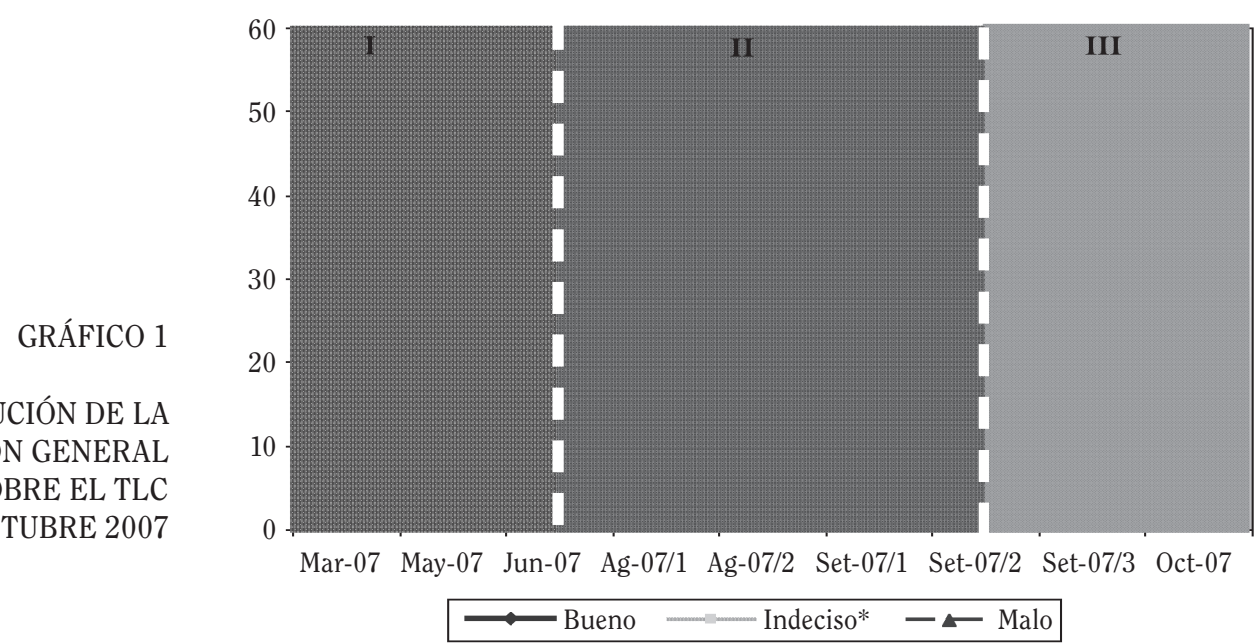

*Incluye la opinión regular, los que no saben y los que no responden. Fuente: PROCESOS. Encuestas TLC marzo-octubre, 2007. 
En el seguimiento de la intención de voto se presenta el mismo patrón que en la opinión general sobre el TLC (Cuadro B2).

\section{CUADRO B2}

INTENCIÓN DE VOTO EN EL REFERÉNDUM SOBRE EL TLC MARZO-OCTUBRE 2007

\begin{tabular}{|c|c|c|c|c|c|c|c|c|c|}
\hline \multirow{2}{*}{$\begin{array}{l}\text { INTENCIÓN DE } \\
\text { VOTO }\end{array}$} & \multicolumn{2}{|c|}{ I } & \multicolumn{4}{|c|}{ II } & \multicolumn{3}{|c|}{ III } \\
\hline & Mar-07 & May-07 & Jun-07 & Ag-07/1 & Ag- $07 / 2$ & Set-07/1 & Set-07/2 & Set-07/3 & Oct- 07 \\
\hline \multicolumn{10}{|c|}{ TOTAL DE ENTREVISTADOS } \\
\hline Voto SÍ & 48,7 & 41,6 & 46,6 & 42,3 & 42,7 & 40,4 & 37,2 & 32,3 & 38,5 \\
\hline Voto NO & 31,6 & 34,0 & 34,9 & 34,7 & 32,3 & 35,3 & 36,5 & 46,0 & 42,4 \\
\hline Indeciso & 13,2 & 17,1 & 13,7 & 15,9 & 18,3 & 18,2 & 18,2 & 14,5 & 11,8 \\
\hline No responde & 6,1 & 6,6 & 4,7 & 7,1 & 6,1 & 5,6 & 5,7 & 4,8 & 3,9 \\
\hline No votará & 0,5 & 0,6 & 0,0 & 0,0 & 0,5 & 0,6 & 2,5 & 2,4 & 3,4 \\
\hline Total & 100,0 & 100,0 & 100,0 & 100,0 & 100,0 & 100,0 & 100,0 & 100,0 & 100,0 \\
\hline ÍNDICE* & $+17,1$ & $+7,6$ & $+11,7$ & $+7,6$ & $+10,4$ & $+5,1$ & $+0,7$ & $-13,7$ & $-3,9$ \\
\hline \multicolumn{10}{|c|}{ SEGUROS DE VOTAR** } \\
\hline $\begin{array}{l}\text { Índice seguros de } \\
\text { votar }\end{array}$ & n.a. & $+12,6$ & $+19,5$ & $+13,1$ & $+15,1$ & $+8,2$ & $+2,9$ & $-11,9$ & $+0,2$ \\
\hline
\end{tabular}

* Índice para el total de los entrevistados = \%Voto SÍ - \%Voto NO.

** Excluye a los que expresan que no piensan votar. Índice seguros de votar = \%Voto Sí - \%Voto NO Fuente: PROCESOS, Encuestas TLC marzo-octubre, 2007.

En el siguiente gráfico se señalan las tres fases de la evolución de la intención de voto en el Referéndum sobre el TLC.
Como se ha señalado, no solo se midió la intención de voto. Además se preguntó sobre la seguridad de votar con el fin de dar seguimiento GRÁFICO 2

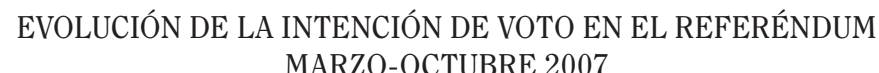
MARZO-OCTUBRE 2007

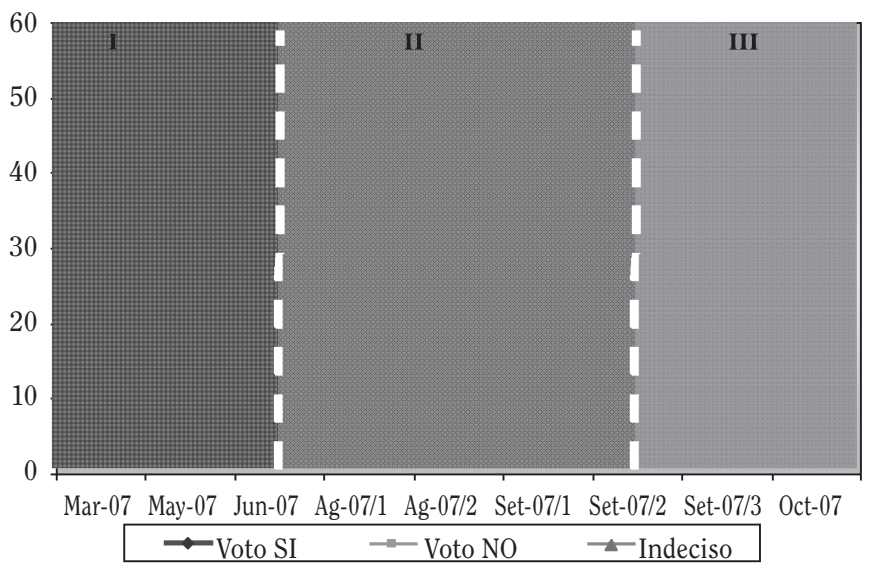

Fuente: PROCESOS. Encuestas TLC marzo-octubre, 2007. 
al grupo de posibles votantes. En el Gráfico 3 -que inicia con datos de mayo del 2007 y presenta el índice de diferencia entre el voto sí $y$ voto NO- se observa que la evolución de los posibles votantes es muy similar a la del conjunto de la población.

GRÁFICO 3
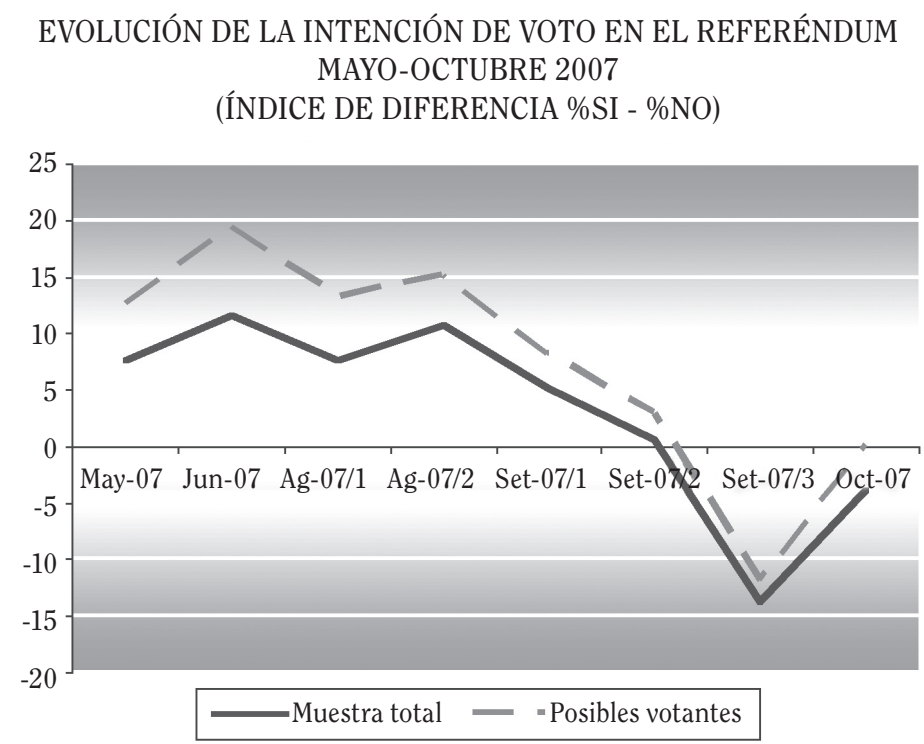

Fuente: PROCESOS. Encuestas TLC mayo - octubre, 2007.

\section{FASE INICIAL: LA INDECISIÓN}

Esta fase comprende el período de marzo a mayo del 2007. Se destaca por un aumento significativo de la indecisión de las personas entrevistadas tanto ante la pregunta general sobre las bondades o no del TLC, así como en intención de voto.

En la pregunta general sobre si el TLC es bueno o malo para el país, el nivel de indecisión subió de $18,7 \%$ a $24,8 \%$, disminuyéndose en especial el grupo que expresaba que era bueno en marzo (Cuadro B1).

Es importante señalar que la intención de voto medida en marzo es una posibilidad teórica, independiente de toda aplicación, pues no se había acordado realizar aún el Referéndum. Mientras que en mayo sí se había decidido llevar adelante el Referéndum. Hecha esta salvedad, se puede notar que el cambio señalado para la pregunta anterior, se da también en esta, aunque en menor magnitud. El nivel de indecisión pasó de $13,7 \%$ a $17,1 \%$ (Cuadro B2).

Se puede plantear la hipótesis de que los cambios señalados en ambas respuestas entre una y otra encuesta podría sugerir una actitud reflexiva de los costarricenses por el cambio entre una situación cuya decisión era responsabilidad del ámbito del Poder Legislativo y una nueva, donde la decisión pasó a manos de la ciudadanía. Es una reacción ante el Referéndum, originada probablemente en la responsabilidad, la incertidumbre y la búsqueda de mejor fundamentación de la opinión.

\section{SEGUNDA FASE: TENDENCIA A LA BAJA DEL APOYO AL TLC Y AL SÍ}

Entre junio y setiembre la evolución del apoyo al TLC pasó de $52,2 \%$ a $46,7 \%$, manteniendo la tendencia a la baja durante todas las mediciones. Si se observa el índice compuesto por la diferencia entre bueno y menos malo, se observa que en el período perdió 10 puntos porcentuales (Cuadro B1).

La intención de voto por el sí mostró también una tendencia a la baja, pasando de una ventaja importante en junio de $46 \%$ a $42 \%$. El índice compuesto por la resta del sí menos el NO evolucionó de 11,7 puntos a 5,1 puntos. 
Debe observarse que durante esta etapa, el No se mantuvo prácticamente igual (Cuadro B2). Solo ocurría una caída del sí.

TERCERA FASE: LA VOLATILIDAD ${ }^{3}$ DEL ÚLTIMO TRAMO DE LA CAMPAÑA Y EL EMPATE FINAL

En la tercera y cuarta semana de setiembre $y$ en la primera de octubre — semana previa a la votación-, se registró una fuerte volatili$\mathrm{dad}^{4}$, entendida como movimientos fuertes con cambios de dirección en plazos muy cortos.

Se dio una aceleración de la baja en el apoyo al sí y una alza correlativa en el del NO, situación que llevó a que en algún momento el NO superara al sí en más de 10 puntos $^{5}$, y una posterior recuperación del sí y baja del No que hizo que la campaña se cerrara con un virtual empate entre ambas fuerzas.

\section{CUADRO B3}

INTENCIÓN DE VOTO EN EL REFERÉNDUM, POR DÍA DURANTE LAS ÚLTIMAS TRES SEMANAS - SUAVIZADA CON PROMEDIOS MÓVILES DE 3 DÍAS-

\begin{tabular}{|c|c|c|c|c|c|c|c|c|c|c|}
\hline \multirow[b]{2}{*}{ FECHA } & \multicolumn{5}{|c|}{ RESULTADOS DIARIOS } & \multicolumn{5}{|c|}{ PROMEDIOS MÓVILES (TRES DÍAS) } \\
\hline & $\begin{array}{c}\text { Entrev. } \\
\text { diarias }\end{array}$ & \%SÍ & $\% \mathrm{NO}$ & \%Indec. & $\begin{array}{l}\text { Dife- } \\
\text { rencia }\end{array}$ & $\begin{array}{l}\text { Entrev. } \\
\text { Acum. }\end{array}$ & \%Sí & $\% \mathrm{NO}$ & \%Indec. & $\begin{array}{l}\text { Dife- } \\
\text { rencia }\end{array}$ \\
\hline 17 setiembre & 90 & 37,8 & 40,0 & 18,9 & $-2,2$ & 90 & 37,8 & 40,0 & 18,9 & $-2,2$ \\
\hline 18 setiembre & 126 & 42,9 & 25,4 & 21,4 & 17,5 & 216 & 40,7 & 31,5 & 20,4 & 9,3 \\
\hline 19 setiembre & 118 & 38,1 & 33,9 & 18,6 & 4,2 & 334 & 39,8 & 32,3 & 19,8 & 7,5 \\
\hline 20 setiembre & 95 & 40,0 & 46,3 & 10,5 & $-6,3$ & 339 & 40,4 & 34,2 & 17,4 & 6,2 \\
\hline 21 setiembre & 86 & 37,2 & 45,3 & 14,0 & $-8,1$ & 299 & 38,5 & 41,1 & 14,7 & $-2,7$ \\
\hline 22 setiembre & 74 & 40,5 & 35,1 & 20,3 & 5,4 & 255 & 39,2 & 42,7 & 14,5 & $-3,5$ \\
\hline 24 setiembre & 42 & 42,9 & 38,1 & 14,3 & 4,8 & 202 & 39,6 & 40,1 & 16,3 & $-0,5$ \\
\hline 26 setiembre & 75 & 33,3 & 41,3 & 21,3 & $-8,0$ & 191 & 38,2 & 38,2 & 19,4 & 0,0 \\
\hline 27 setiembre & 94 & 35,1 & 42,6 & 13,8 & $-7,4$ & 211 & 36,0 & 41,2 & 16,6 & $-5,2$ \\
\hline 28 setiembre & 84 & 34,5 & 52,4 & 9,5 & $-17,9$ & 253 & 34,4 & 45,5 & 14,6 & $-11,1$ \\
\hline 29 setiembre & 85 & 32,9 & 47,1 & 14,1 & $-14,1$ & 263 & 34,2 & 47,1 & 12,5 & $-12,9$ \\
\hline 1 octubre & 112 & 41,1 & 38,4 & 15,2 & 2,7 & 281 & 36,7 & 45,2 & 13,2 & $-8,5$ \\
\hline 2 octubre & 113 & 43,4 & 44,2 & 8,0 & $-0,9$ & 310 & 39,7 & 42,9 & 12,3 & $-3,2$ \\
\hline 3 octubre & 94 & 41,5 & 34,0 & 16,0 & 7,4 & 319 & 42,0 & 39,2 & 12,9 & 2,8 \\
\hline 4 octubre & 77 & 40,3 & 51,9 & 7,8 & $-11,7$ & 284 & 41,9 & 43,0 & 10,6 & $-1,1$ \\
\hline 5 octubre & 52 & 40,4 & 38,5 & 17,3 & 1,9 & 223 & 40,8 & 41,3 & 13,5 & $-0,4$ \\
\hline
\end{tabular}

Fuente: PROCESOS, Encuestas TLC setiembre y octubre, 2007.

La volatilidad electoral se ha entendido en la ciencia política en dos sentidos diferentes. Por un lado, como el cambio en apoyo electoral hacia los partidos políticos entre una elección y otra (Drummond, Andrew J. 2006, "Electoral Volatility and Party Decline in Western Democracies: 1970-1995". Political Studies 54.3, octubre. 2006. Por otro lado, se ha usado volatitlidad para describir períodos de alta inestabilidad en una misma campaña electoral (Véase por ejemplo http://www.ipsos-mori.com/content/ publications/electoral-volatility1.ashx), inspirado en el concepto de volatilidad de los mercados financieros (Poon, 2005).
5 Aunque los tamaños de las muestras en las cuales se basan los promedios móviles no son muy grandes - entre 200 y 300 en su mayoría- y hay un efecto aleatorio en las variaciones, no queda duda que el principal componente es la volatilidad de las intenciones, o sea los cambios en las preferencias de los electores. Por otra parte, la tendencia gradual al descenso de la proporción de indecisos, sugiere que las oscilaciones no se deben a cambios fuertes en la proporción de indecisos.

6 La alza del no y la baja del SI en la penúltima semana coincide con los resultados de la encuesta realizada por UNIMER para La Nación, publicada hasta en el día 4 de octubre del 2007. 
Este comportamiento volátil de los electores queda claro en las cifras del Cuadro B3 $y$ en el Gráfico 4, donde se presentan, para los posibles votantes, las intenciones de voto diarias de las últimas tres semanas de la campaña, "suavizadas" por medio de promedios móviles de tres días ${ }^{6}$.

\section{GRÁFICO 4}

\section{EVOLUCIÓN DE LA INTENCIÓN DE VOTO DE LOS POSIBLES VOTANTES EN LAS ÚLTIMAS TRES SEMANAS DE LA CAMPAÑA DEL REFERÉNDUM (DATOS DIARIOS SUAVIZADOS CON PROMEDIO DE TRES DÍAS)}

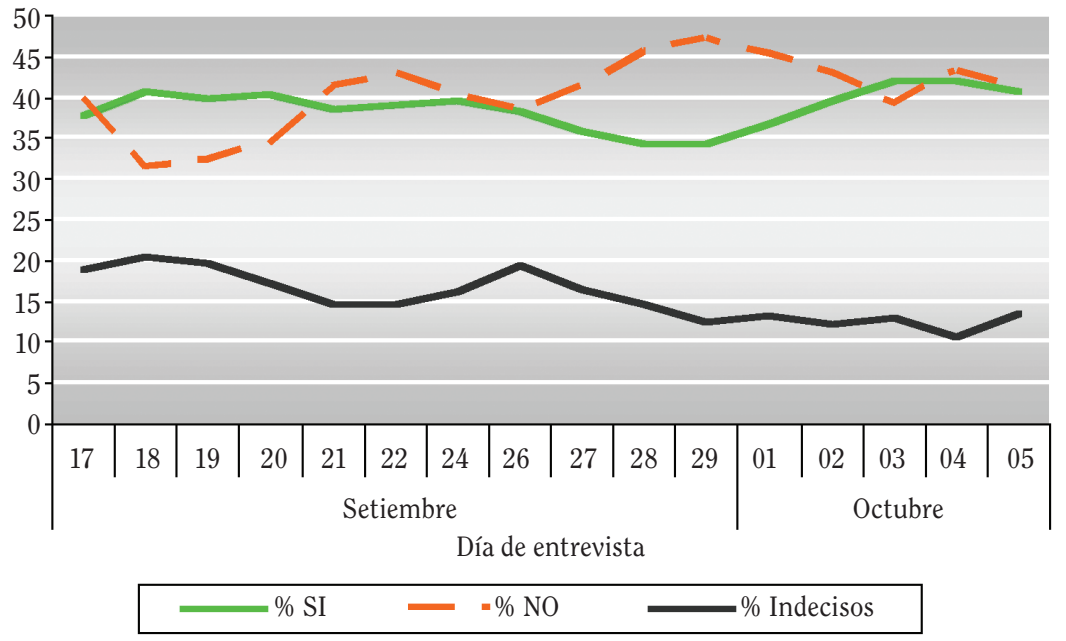

Fuente: PROCESOS. Encuestas TLC setiembre y octubre, 2007.

Una mejor apreciación de la volatilidad de las intenciones de voto en las últimas semanas de la campaña puede lograrse usando el valor del indicador de diferencia \%sí - \%NO que aparece en la última columna del Cuadro B3, y que corresponde a los valores diarios "suavizados" con promedios móviles de tres días (Gráfico 5).

Puede notarse que el margen del sí sobre el No pasa de positivo a negativo y de un máximo de
9,3 a un mínimo de -12,9 en un período corto, $y$ finalmente se recobra para cerrar prácticamente en cero en los días previos a la elección, es decir, un virtual empate.

En esta volatilidad final de la campaña sobre el TLC influyeron muchos elementos. Se les puede distinguir entre estructurales y coyunturales. Entre los primeros se pueden señalar:

$7 \quad$ Note que las cifras son para los posibles votantes, es decir, se excluyen los que expresaron que no pensaban votar. 


\section{GRÁFICO 5}

EVOLUCIÓN DEL ÍNDICE DE INTENCIÓN DE VOTO

DE LOS POSIBLES VOTANTES

(ÚLTIMAS TRES SEMANAS DE LA CAMPAÑA DEL REFERÉNDUM)

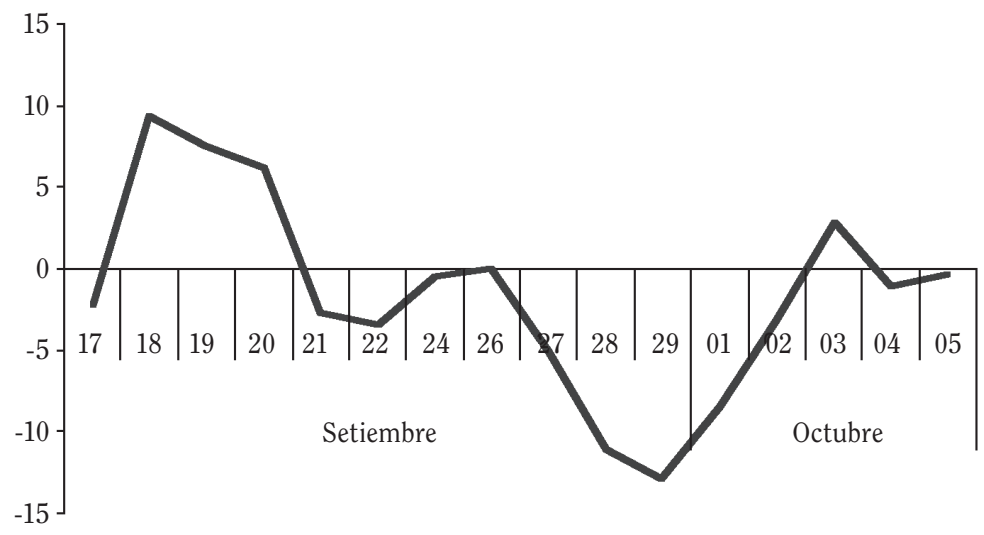

Fuente: PROCESOS. Encuestas TLC setiembre y octubre, 2007.

$\diamond$ la novedad del instrumento del Referéndum,

$\diamond$ la diferencia de escoger entre un candidato versus tener al frente un proyecto de ley,

$\diamond \quad$ la creciente disminución de lealtad partidaria entre la población costarricense (Rodríguez, et ál., 2005; Rodríguez y Castro, 1999).

Adicionalmente se dieron elementos coyunturales como la polarización de la comunicación, la intensificación final de todo tipo de comunicación, el activismo de los dirigentes, la batalla de los rumores, el esfuerzo de la prensa por mostrar las bondades o los defectos del TLC, $y$ una serie final de eventos mediáticos.

Entre los eventos mediáticos se pueden citar:

$\diamond$ la publicación de un Memorándum escrito por el Segundo Vicepresidente de la República, la crítica por él mismo y finalmente la renuncia del Vicepresidente el 22 de setiembre,

$\diamond$ las visitas patrocinadas por el Partido Acción Ciudadana (PAC) del 23 de setiembre del Congresista Michael Michaud y del Senador Bernie Sanders que aseguran que los beneficios de la Cuenca del Caribe (ICC) no se le eliminarán al país, de no aprobarse el TLC,

$\diamond$ el 26 de setiembre la Asamblea Legislativa queda paralizada luego de que 25 de sus miembros abandonan el plenario para hacer campaña,

$\diamond$ el 26 de setiembre 94 sacerdotes católicos, de zonas fuera de la Región Metropolitana hacen un llamado vehemente a votar por el NO,

$\diamond$ un evento mediático que no tuvo el resultado esperado fue la marcha final del NO (30 de setiembre) que pese a ser de importante tamaño, tuvo muy baja cobertura de los medios,

$\diamond$ el 4 de octubre, último día de campaña pagada ocurren varios hechos importantes:

- el comunicado de prensa de la Secretaria del Departamento de Comercio de Estados Unidos Susan Schwab que sostiene lo contrario del Senador Michaud y el Congresista Sanders,

- un evento que cambia de dirección: la conferencia de prensa de fracción del PAC que llama por teléfono a Linda Sánchez, congresista demócrata por su opinión a favor de renegociación. Sin embargo, esta resultó en contra de la posibilidad de permanencia de ICC,

- el periódico La Nación publica encuesta que da triunfo al NO con 55\%, sí $43 \%$, reactivando las fuerzas del sí,

$\diamond$ el 5 de octubre el ex Presidente Luis Alberto Monge pide el voto por el NO aduciendo que el TLC lesionaría la soberanía del país, 
$\diamond$ el 5 de octubre se da una entrevista realizada por Alberto Padilla de CNN al economista de Georgetown Ricardo Ernst - a favor del TLC-, sobre la situación de Costa Rica en caso de que no se lograse la aprobación del Tratado de Libre Comercio,

$\diamond$ el 6 y 7 de octubre se retransmitió esa entrevista varias veces por la estación nacional de noticias por televisión REPRETEL.

\section{PARTE C: EVOLUCIÓN DE INDICADORES DE PRINCIPALES TEMAS EN DISPUTA}

En esta sección se presentará la evolución de algunos indicadores considerados como principales para la comprensión de la opinión pública alrededor del Referéndum. Los cuadros y gráficos se construyeron con los estudios de mayo a octubre del 2007, cuando ya se sabía que se iba a hacer un Referéndum.

\section{PROPORCIÓN QUE SE SIENTE RAZONABLEMENTE} INFORMADA SOBRE EL TLC

En cuanto al grado de información acerca del TLC de cada entrevistado, según su propio criterio, se observa en el Cuadro $\mathrm{C} 1$ una tendencia al alza de quienes se sienten muy informados más quienes se sienten razonablemente informados. Sin embargo, al final de la campaña del TLC, este grupo apenas llega a estar empatado con quienes se sienten poco o nada informados.

\section{CUADRO C1}

NIVEL DE INFORMACIÓN SOBRE EL TLC MAYO-OCTUBRE 2007

\begin{tabular}{lcccccccc}
\hline NIVEL DE & \multicolumn{1}{c}{ I } & \multicolumn{3}{c}{ II } & \multicolumn{3}{c}{ III } \\
${$\cline { 2 - 6 }$} }$ & May-07 & Jun-07 & Ag-07/1 & Ag-07/2 & Set-07/1 & Set-07/2 & Set-07/3 & Oct-07 \\
\hline Muy informado & 4,7 & 11,4 & 7,0 & 8,8 & 10,7 & 12,0 & 13,14 & 14,4 \\
Razonablemente & 30,0 & 27,6 & 30,4 & 30,6 & 29,1 & 34,6 & 32,17 & 34,3 \\
informado & 52,1 & 50,1 & 48,3 & 46,8 & 48,3 & 43,1 & 43,16 & 42,2 \\
Poco informado & 12,9 & 10,6 & 13,6 & 12,8 & 10,7 & 10,1 & 11,26 & 9,1 \\
Nada informado & 0,3 & 0,3 & 0,7 & 1,0 & 1,1 & 0,1 & 0,27 & - \\
NS/NR & $-30,3$ & $-21,6$ & $-24,6$ & $-20,1$ & $-19,3$ & $-6,6$ & $-9,1$ & $-2,6$ \\
ÍnDICE* & & & & & & & &
\end{tabular}

$*$ Índice $=(\%$ Muy informado $+\%$ Razonablemente informado $)-(\%$ Poco informado $+\%$ Nada informado $)$.

Fuente: PROCESOS, Encuestas del TLC mayo-octubre, 2007.

En el gráfico 6 con el índice del nivel de información sobre el TLC (\%Muy informado + \%Razonablemente informado - \%Poco informado $+\%$ Nada informado), se aprecia la tendencia al incremento del mismo en una relación prácticamente lineal entre el nivel de información y el tiempo. Sin embargo, el último dato aún es negativo.
Estos resultados merecen un análisis específico por parte de quienes elaboraron las campañas del sí y del No, pues pese al esfuerzo enorme que hacen por transmitir sus puntos de vista, no logran satisfacer al final a la mitad de la población. 


\section{GRÁFICO 6}

EVOLUCIÓN DEL ÍNDICE DEL NIVEL

INFORMACIÓN SOBRE EL TLC

MAYO-OCTUBRE 2007

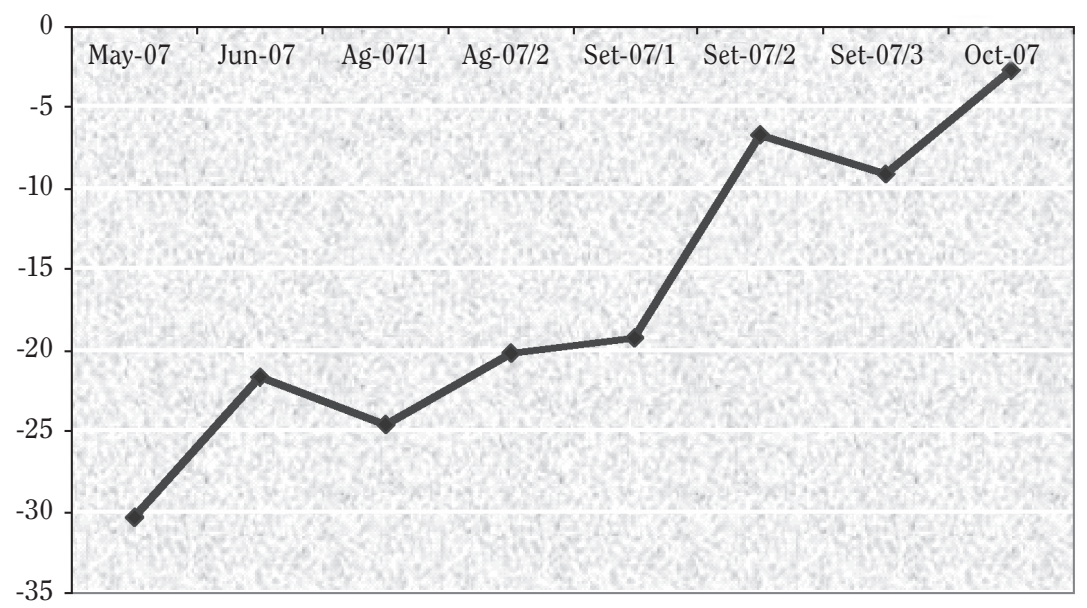

Fuente: PROCESOS. Encuestas TLC mayo-octubre, 2007.

LOS POSIBLES EFECTOS SOBRE EL PAÍS

Esta sección cubre dos temas: la percepción sobre los posibles efectos económicos y sociales del TLC y la percepción sobre los posibles efectos del TLC sobre la soberanía del país.

Para la medición de los efectos económicos y sociales se utilizaron tres preguntas.
Una primera sobre si los beneficios del TLC eran solo económicos o eran económicos y sociales, una segunda sobre si con el TLC se perderían más empleos de los que se ganaban y la tercera sobre si con el Tratado podían ganar ambos países o solo Estados Unidos. En el Cuadro C2 y en el Gráfico 7 se presentan los resultados de las primeras preguntas.

\section{CUADRO C2}

EFECTOS ECONÓMICOS Y SOCIALES DEL TLC SOBRE COSTA RICA MAYO-OCTUBRE 2007

\begin{tabular}{|c|c|c|c|c|c|c|c|c|}
\hline & I & \multicolumn{4}{|c|}{ II } & \multicolumn{3}{|c|}{ III } \\
\hline & May-07 & Jun-07 & Ag-07/1 & Ag-07/2 & Set-07/1 & Set-07/2 & Set-07/3 & Oct- 07 \\
\hline \multicolumn{9}{|c|}{ Con el TLC se obtiene beneficio económico y social o solo económico } \\
\hline $\begin{array}{l}\text { Beneficio } \\
\text { económico y } \\
\text { social (1) }\end{array}$ & 42,5 & 36,0 & 41,2 & 39,8 & 41,3 & 32,7 & 34,0 & 37,3 \\
\hline $\begin{array}{l}\text { Sólo beneficio } \\
\text { económico (2) }\end{array}$ & 28,6 & 31,1 & 29,3 & 28,4 & 26,3 & 28,2 & 31,1 & 28,1 \\
\hline $\begin{array}{l}\text { Ni beneficio } \\
\text { económico ni } \\
\text { social }\end{array}$ & 23,2 & 26,9 & 24,5 & 24,8 & 25,9 & 33,0 & 30,8 & 31,7 \\
\hline
\end{tabular}




\begin{tabular}{lcccccccc}
\hline & I & \multicolumn{4}{c}{ II } & \multicolumn{3}{c}{ III } \\
\cline { 2 - 8 } NS/NR & May-07 & Jun-07 & Ag-07/1 & Ag-07/2 & Set-07/1 & Set-07/2 & Set-07/3 & Oct-07 \\
\cline { 2 - 9 } ÍNDICE* & 5,6 & 6,0 & 4,0 & 6,1 & 5,0 & 5,6 & 4,1 & 2,9 \\
\hline \multicolumn{2}{l}{ Con el TLC se perderán más empleos de los que se ganan } & & & & & & \\
Sí & $+13,9$ & $+5,0$ & $+11,9$ & $+11,4$ & $+15,0$ & $+4,5$ & $+3,0$ & $+9,2$ \\
No & 31,0 & 31,6 & 31,1 & 27,6 & 29,9 & 35,8 & 38,5 & 36,2 \\
NS/NR & 59,2 & 58,5 & 60,4 & 62,0 & 60,4 & 56,0 & 55,0 & 56,3 \\
ÍNDICE** & 9,8 & 9,9 & 8,5 & 10,4 & 9,7 & 8,2 & 6,5 & 7,6 \\
\hline
\end{tabular}

*Índice $=(1)-(2)$

$* *$ Índice $=\%$ No $-\%$ Si.

Fuente: PROCESOS, Encuestas de TLC mayo-octubre, 2007.

\section{GRÁFICO 7}

\section{EVOLUCIÓN DEL ÍNDICE DE LOS EFECTOS ECONÓMICOS Y SOCIALES DEL TLC SOBRE COSTA RICA MAYO-OCTUBRE 2007}

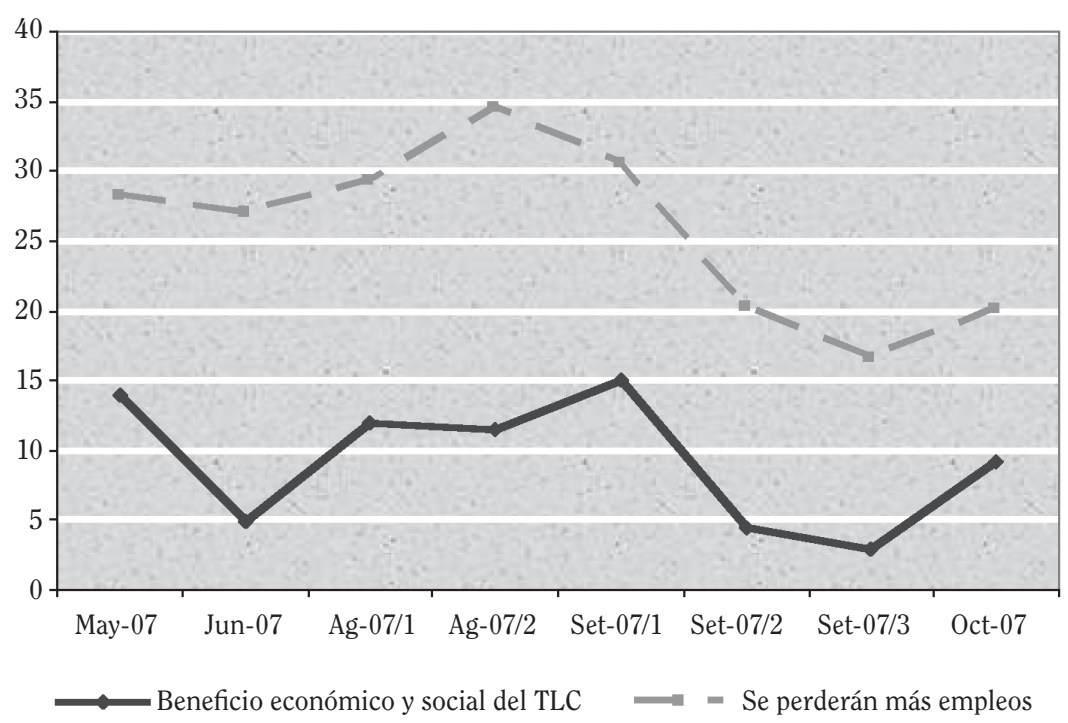

Fuente: PROCESOS. Encuestas TLC mayo-octubre 2007

En esta serie de preguntas se puede observar que el tema de empleo fue el más sólido a favor del TLC de los tres, predominando en toda la campaña la visión de que se creaban más empleos. Las respuestas a las otras dos preguntas mostraron más inestabilidad hacia el final, en las últimas dos mediciones de setiembre y la de octubre, especialmente la opinión sobre el país ganador (Cuadro C3 y Gráfico 8). 


\section{CUADRO C3}

OPINIÓN SOBRE CUÁL SERÁ EL PAÍS GANADOR CON EL TLC ENTRE ESTADOS UNIDOS (EU) COSTA RICA (CR) MAYO-OCTUBRE 2007

\begin{tabular}{lcccccccc}
\hline \multirow{2}{*}{$\begin{array}{l}\text { PAÍS } \\
\text { GANADOR }\end{array}$} & \multicolumn{1}{c}{ I } & \multicolumn{3}{c}{ II } & \multicolumn{3}{c}{ III } \\
\cline { 2 - 9 } & May-07 & Jun-07 & Ag-07/1 & Ag-07/2 & Set-07/1 & Set-07/2 & Set-07/3 & Oct-07 \\
\hline CR y EU & 49,2 & 51,1 & 52,8 & 52,4 & 50,4 & 47,2 & 44,1 & 48,4 \\
Solo EU & 41,0 & 44,6 & 42,6 & 42,2 & 44,9 & 46,6 & 50,9 & 46,2 \\
NS/NR & 9,8 & 4,3 & 4,6 & 5,3 & 4,7 & 5,9 & 5,0 & 5,3 \\
ÍNDICE* & $+8,1$ & $+6,4$ & $+10,2$ & $+10,2$ & $+5,5$ & $+0,6$ & $-6,8$ & $+2,2$ \\
\hline
\end{tabular}

*Índice $=(\% \mathrm{CR} y \mathrm{EUA})-(\%$ Solo EU $)$.

Fuente: PROCESOS, Encuestas del TLC mayo-octubre, 2007.

\section{GRÁFICO 8}

EVOLUCIÓN DEL ÍNDICE DEL PAÍS GANADOR CON EL TLC MAYO-OCTUBRE 2007

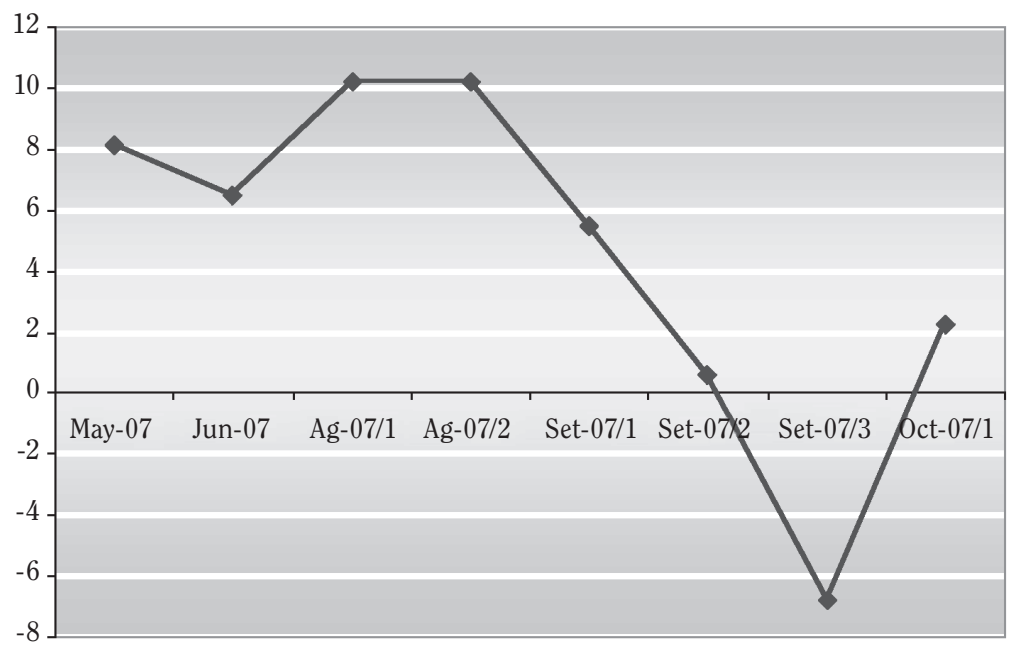

Fuente: PROCESOS. Encuestas TLC mayo-octubre, 2007.

En este último tema acerca de si es posible que ganen ambos países, las opiniones estuvieron divididas $y$ en un momento fueron más los que pensaban que ganaba Estados Unidos (Cuadro C3 y Gráfico 8).

En el tema de la soberanía se analizan tres preguntas: si Estados Unidos tendría mucha influencia en los asuntos internos de Costa Rica con el TLC, si Costa Rica perdería independencia y soberanía, y finalmente si Costa Rica podría aplicar sus propias leyes (Cuadro C4 y Gráfico 9). 


\section{CUADRO C4}

EFECTOS DEL TLC SOBRE LA SOBERANÍA DE COSTA RICA MAYO-OCTUBRE 2007

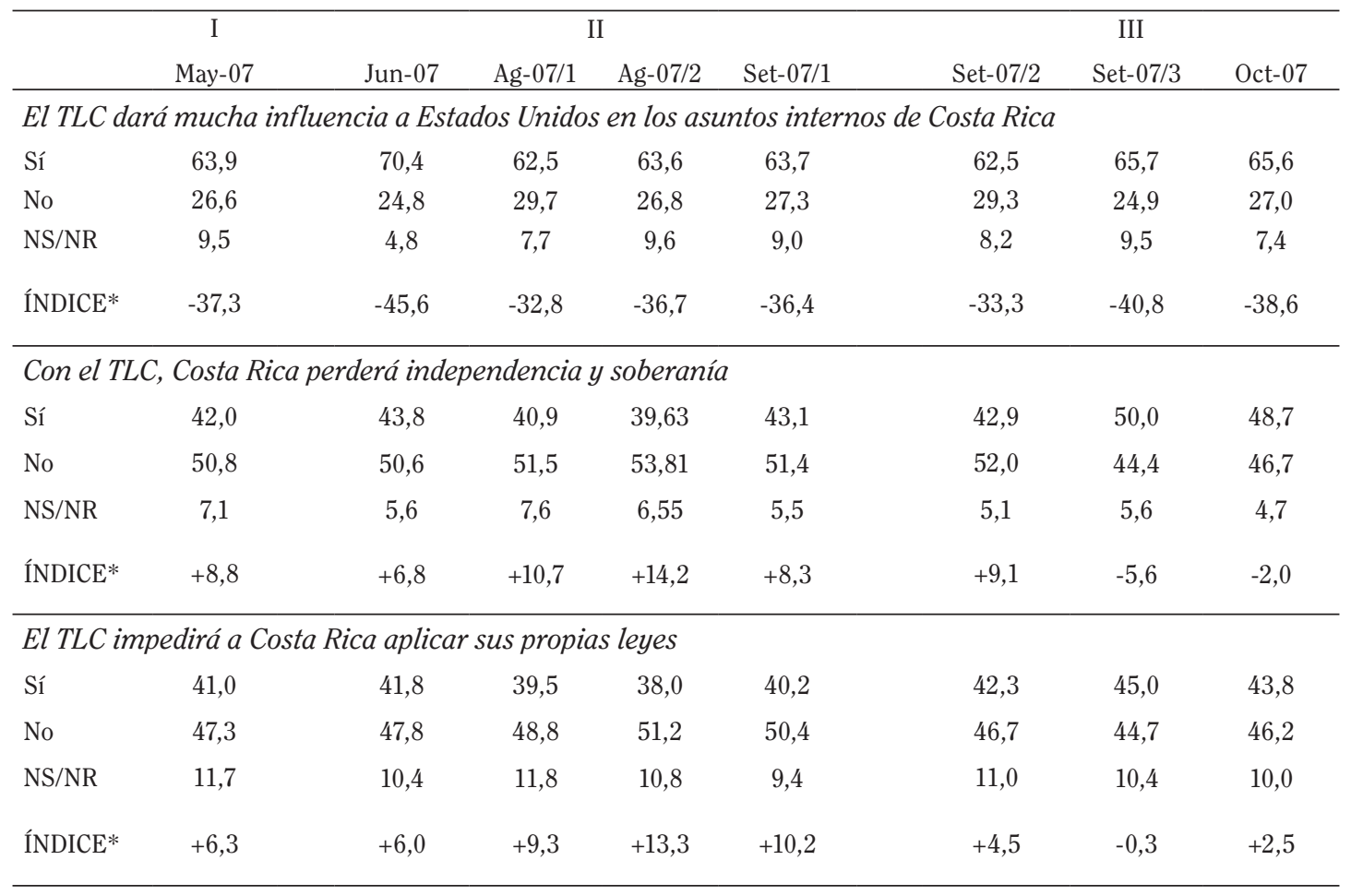

* Índice $=\%$ No $-\%$ Sí.

Fuente: PROCESOS, Encuestas del TLC mayo-octubre, 2007.

\section{GRÁFICO 9}

EVOLUCIÓN DEL ÍNDICE DE LOS EFECTOS DEL TLC SOBRE LA SOBERANÍA DE COSTA RICA MAYO-OCTUBRE 2007

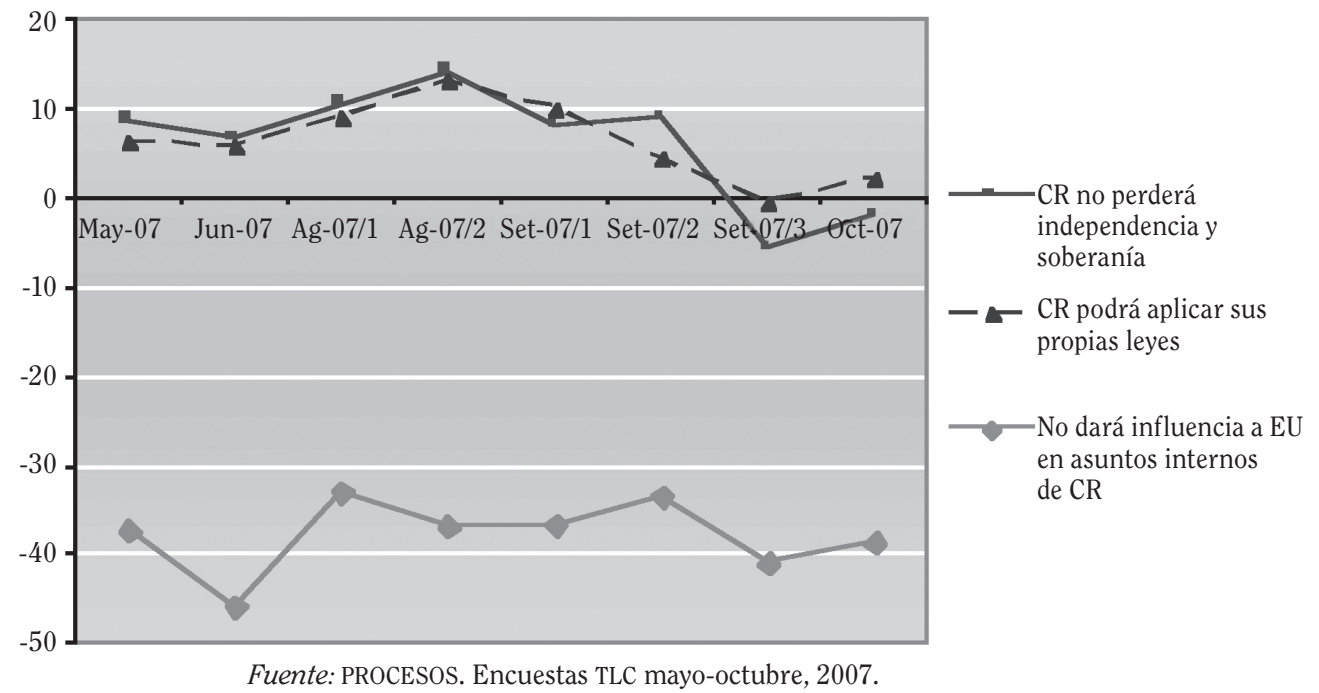


Los datos muestran una opinión mayoritaria y estable en el sentido de que Estados Unidos tendrá mucha influencia sobre nuestro país. Aún en los puntos más bajos de la serie, más del $62 \%$ opinó así. La posibilidad de Costa Rica de aplicar sus propias leyes tendió a dividir a la población, con la excepción de agosto y la primera medición de setiembre. El aspecto de independencia y soberanía, también dividió a la población y tuvo un índice positivo con la excepción de las dos últimas semanas.

LOS POSIBLES EFECTOS NEGATIVOS

DEL TLC SOBRE EL ESTADO SOLIDARIO

Un tema recurrente de discusión durante la campaña acerca del TLC fue el Estado y su papel en la construcción de las oportunidades y la solidaridad. Tres servicios públicos vinculados a este ámbito son: la telefonía celular, la educación pública y la salud. Para medir la opinión de la relación del TLC con estos tres aspectos se elaboraron tres preguntas, una sobre la privatización del Instituto Costarricense de Electricidad (ICE), otra sobre educación y salud y una tercera sobre la Caja Costarricense de Seguro Social (CCSS). Las opciones de respuesta eran en todos los casos sí o no, donde el sí es una respuesta de quienes perciben que el TLC deteriora el Estado Solidario y el no de quienes piensan lo contrario. La distribución de las respuestas aparece en el Cuadro C5 y la evolución del índice (\%NO-\%sí) para las tres preguntas se observa en el Gráfico 10.

\section{CUADRO C5}

EFECTOS DEL TLC SOBRE EL ESTADO SOLIDARIO MAYO-OCTUBRE 2007

\begin{tabular}{|c|c|c|c|c|c|c|c|c|}
\hline & $\mathrm{I}$ & \multicolumn{4}{|c|}{ II } & \multicolumn{3}{|c|}{ III } \\
\hline & May-07 & Jun-07 & Ag-07/1 & Ag- $07 / 2$ & Set-07/1 & Set- $07 / 2$ & Set- $07 / 3$ & Oct-07 \\
\hline \multicolumn{9}{|c|}{ TLC obligará a privatizar el ICE } \\
\hline Sí & 51,7 & 49,9 & 43,8 & 43,4 & 39,3 & 46,9 & 44,1 & 42,9 \\
\hline No & 37,6 & 37,4 & 44,1 & 42,4 & 47,5 & 44,6 & 44,7 & 50,4 \\
\hline $\mathrm{NS} / \mathrm{NR}$ & 10,7 & 12,7 & 12,1 & 14,2 & 13,2 & 8,5 & 11,2 & 6,7 \\
\hline ÍNDICE* & $-14,1$ & $-12,5$ & $+0,3$ & $-1,1$ & $+8,2$ & $-2,3$ & $+0,6$ & $+7,6$ \\
\hline
\end{tabular}

TLC obligará a reducir los servicios de salud y educación que brinda el Estado

\begin{tabular}{ccccccccc} 
Sí & 32,2 & 38,3 & 36,1 & 32,9 & 35,2 & 39,0 & 39,9 & 40,0 \\
No & 57,3 & 53,2 & 55,3 & 56,1 & 58,0 & 51,5 & 52,7 & 53,3 \\
NS/NR & 10,5 & 8,4 & 8,7 & 11,0 & 6,8 & 9,4 & 7,4 & 6,7 \\
ÍNDICE* & $+25,1$ & $+14,9$ & $+19,2$ & $+23,2$ & $+22,8$ & $+12,5$ & $+12,7$ & $+13,4$ \\
\hline
\end{tabular}

TLC provocará la quiebra de la Caja Costarricense del Seguro Social

\begin{tabular}{ccccccccc} 
Sí & 33,1 & 38,2 & 29,3 & 30,3 & 29,4 & 33,1 & 35,2 & 33,0 \\
No & 50,3 & 49,6 & 57,4 & 56,6 & 60,5 & 57,7 & 56,5 & 56,7 \\
NS/NR & 16,6 & 12,2 & 13,2 & 13,1 & 10,0 & 9,1 & 8,3 & 10,3 \\
ÍNDICE* & $+17,2$ & $+11,3$ & $+28,2$ & $+26,2$ & $+31,1$ & $+24,6$ & $+21,3$ & $+23,7$ \\
\hline
\end{tabular}

*Índice $=\%$ No $-\%$ Sí.

Fuente: PROCESOS, Encuestas TLC, mayo-noviembre, 2007. 


\section{GRÁFICO 10}

\section{EVOLUCIÓN DEL ÍNDICE DE LOS EFECTOS DEL TLC SOBRE EL ESTADO SOLIDARIO MAYO-OCTUBRE 2007}

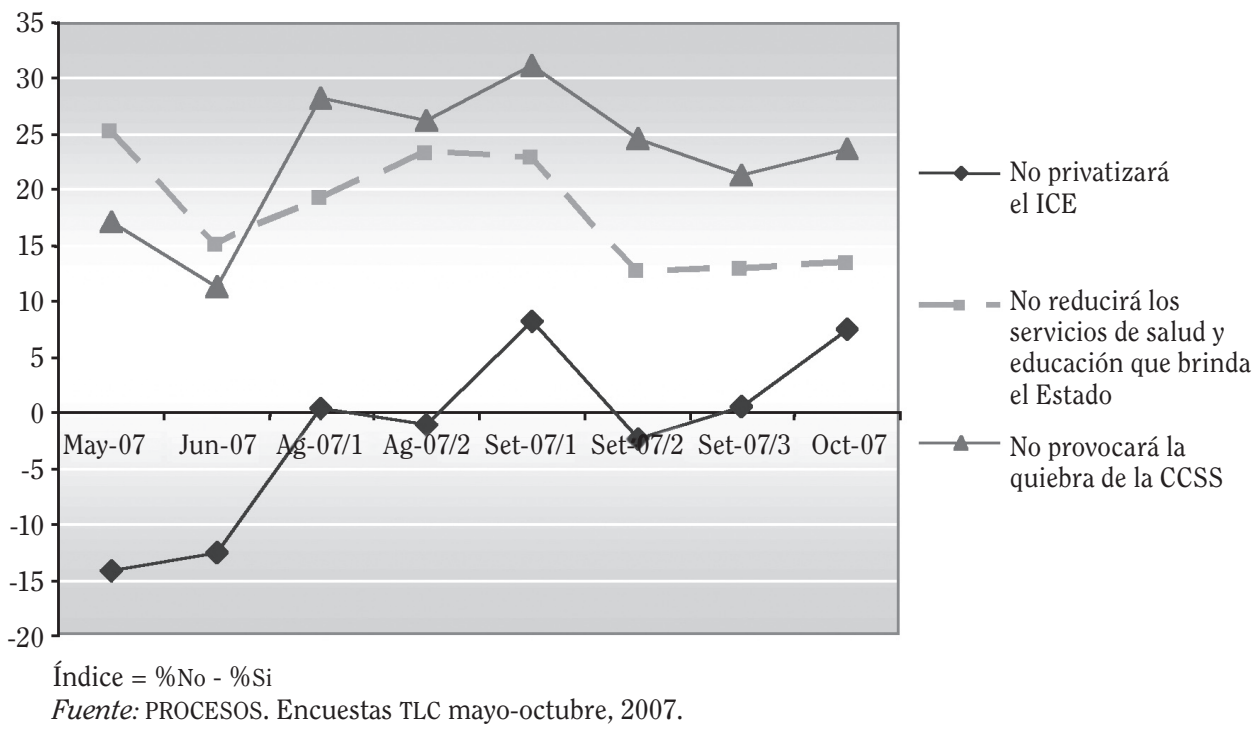

El tema más polémico fue el de la apertura de telecomunicaciones del ICE ${ }^{7}$. En agosto $y$ en la segunda quincena de setiembre se dio un empate en la opinión sobre si el TLC obligaría a privatizar el $\mathrm{ICE}^{8}$. A final de octubre se dio un cambio a favor de la opinión de que no privatizaría el ICE.

En el caso de los servicios de salud y educación, así como con la institución de la CCSS, el porcentaje de respuesta de que no se deteriorarían con el TLC fue siempre mayor que los que opinaban lo contrario. Sin embargo se observan fluctuaciones importantes en ambas preguntas como lo muestran los índices y los gráficos respectivos.

El tema de mayor protesta de los últimos años antes del TLC fue alrededor de la apertura de las telecomunicaciones en el año 2000. Pese ha haberse aprobado dicha apertura, la protesta popular llevó al entonces Presidente Rodríguez (19982002) a retroceder.
LOS POSIBLES EFECTOS DEL TLC SOBRE LOS GRUPOS PERCIBIDOS COMO VULNERABLES

Otro gran tema de discusión en la agenda nacional durante el período del TLC, fue su impacto sobre grupos vulnerables: los pobres, los pequeños agricultores, los pequeños empresarios. También se dio seguimiento a la percepción sobre el impacto a los educadores y los empleados públicos. Para cada uno de ellos se realizó una pregunta en forma repetida durante el tiempo del estudio (Cuadro C6).

Se observa que otra opinión sólidamente establecida en la opinión pública fue que el TLC no beneficiaría a las personas pobres y con pocos estudios ni a los pequeños agricultores.

$9 \quad$ Otra serie de preguntas sobre el ICE y el INS permitió establecer que la mayoría de los costarricenses distinguía entre privatización, monopolio y apertura. 
CUADRO C6

EFECTOS DEL TLC SOBRE LOS GRUPOS PERCIBIDOS COMO VULNERABLES MAYO-OCTUBRE 2007

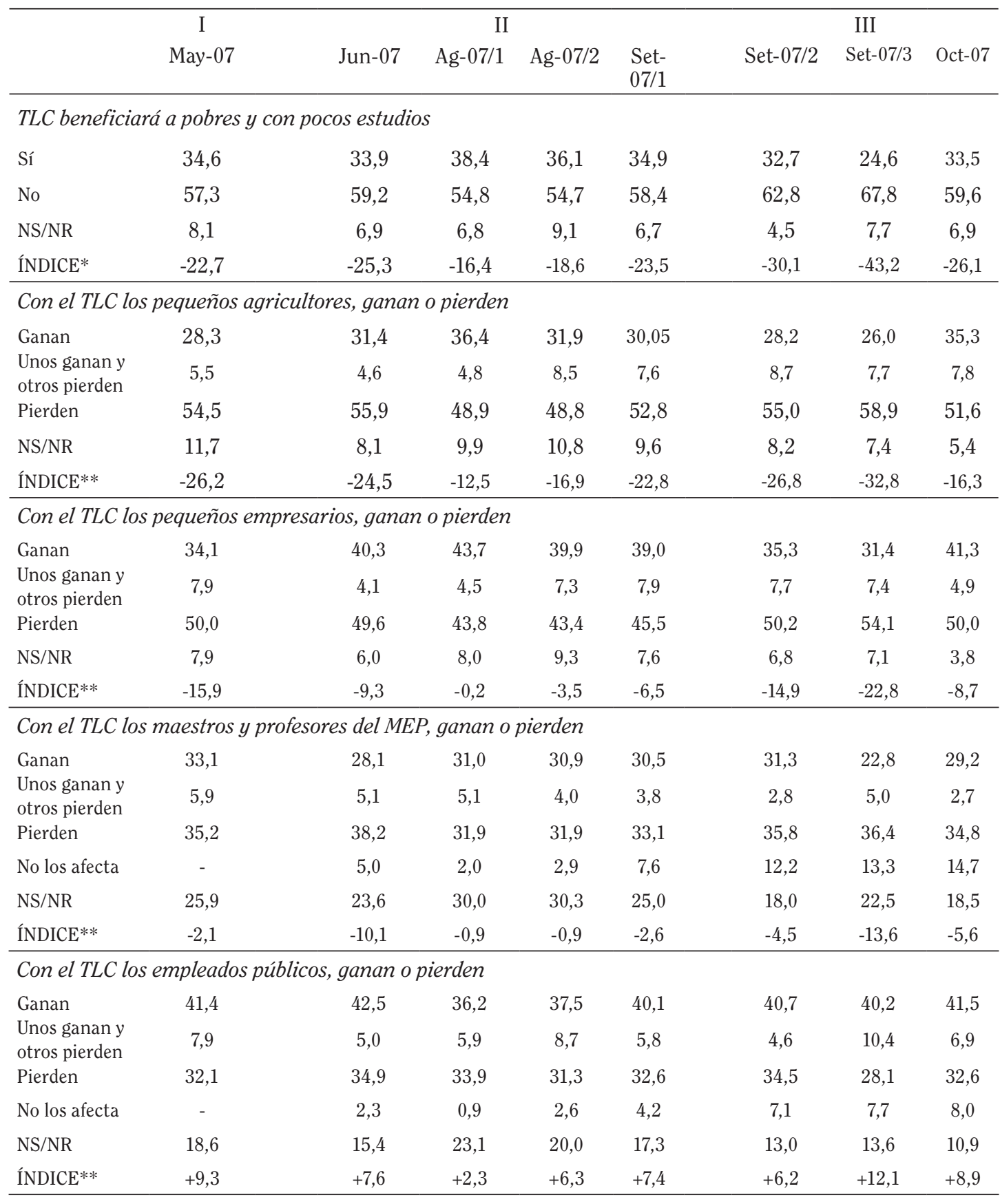

*Índice $=\%$ No $-\%$ Sí.

**Índice $=\%$ Ganan $-\%$ Pierden.

Fuente: PROCESOS, Encuestas TLC mayo-octubre, 2007. 
Los índices siempre fueron negativos, $y$ empeoraron en las dos últimas mediciones de setiembre.

Los pequeños empresarios, los educadores y los empleados públicos mantuvieron a la población más dividida. En todos los casos se nota la crisis del sí hacia el final de setiembre.

Para cada una de las cinco preguntas sobre pobres, pequeños agricultores, peque- ños empresarios, educadores y empleados públicos, se hizo un gráfico con la evolución de la diferencia entre \%No-\%Sí y $\%$ Ganan-\%Pierden, según corresponda. Se observa con claridad que la opinión sobre los primeros tres grupos percibidos como vulnerables evoluciona en forma paralela (Gráfico 11).

\section{GRÁFICO 11}

EVOLUCIÓN DEL ÍNDICE DE LOS EFECTOS DEL TLC SOBRE LOS PEQUEÑOS EMPRESARIOS Y POBRES MAYO-OCTUBRE 2007

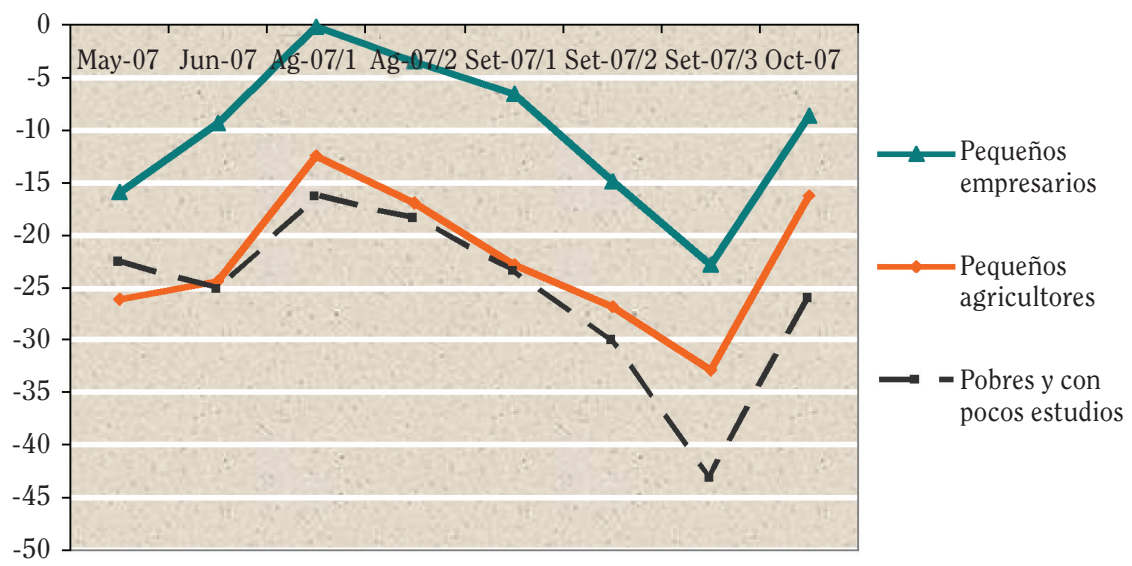

Fuente: PROCESOS. Encuestas TLC mayo-octubre, 2007.

El índice para los otros dos grupos tiene un comportamiento más individualizado, tal y como se presenta en el siguiente gráfico.
Los empleados públicos no fueron vistos por la mayoría como grupo perdedor.

GRÁFICO 12

EVOLUCIÓN DEL ÍNDICE DE LOS EFECTOS DEL TLC SOBRE LOS EMPLEADOS PÚBLICOS Y LOS EDUCADORES MAYO-OCTUBRE 2007

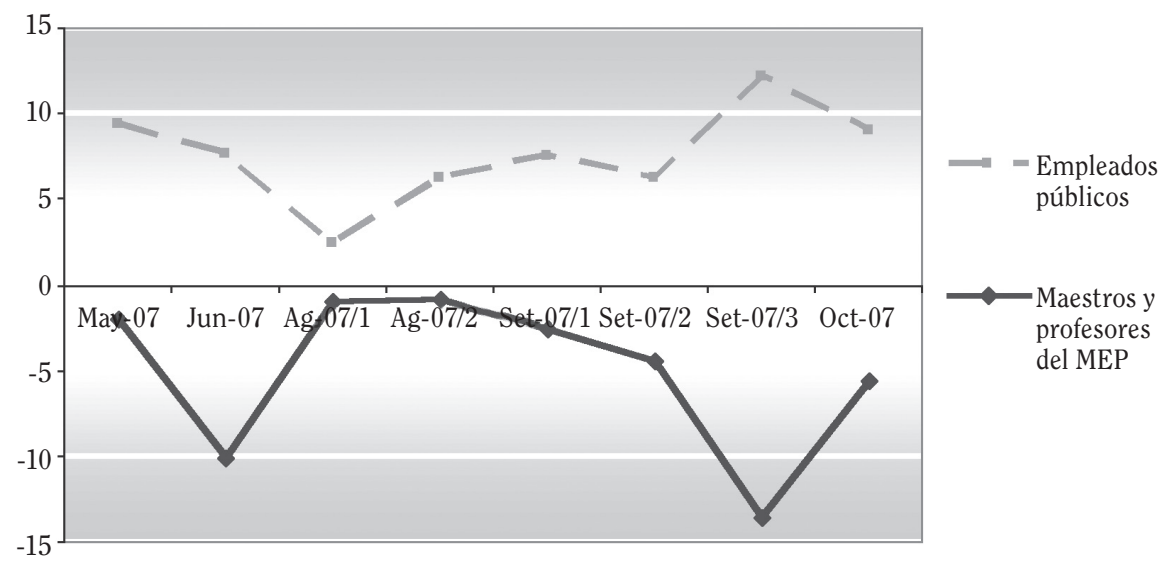

Fuente: PROCESOS. Encuestas TLC mayo-octubre, 2007. 
LOS POSIBLES EFECTOS DEL TLC

SOBRE LA PERSONA ENTREVISTADA

Aparte de los efectos sobre el Estado solidario, grupos vulnerables y la soberanía del país, se le dio seguimiento al impacto del TLC a nivel personal o familiar. Los resultados se muestran en el Cuadro C7 y en el Gráfico 13.

\section{CUADRO C7}

EFECTOS DEL TLC SOBRE LA PERSONA ENTREVISTADA Y SU FAMILIA MAYO-OCTUBRE 2007

\begin{tabular}{lcccccccc}
\hline & I & \multicolumn{3}{c}{ II } & \multicolumn{3}{c}{ III } \\
\cline { 2 - 9 } & May-07 & Jun-07 & Ag-07/1 & Ag-07/2 & Set-07/1 & Set-07/2 & Set-07/3 & Oct-07 \\
\hline Beneficia & 30,3 & 30,1 & 29,3 & 31,9 & 30,8 & 26,5 & 27,2 & 32,1 \\
Perjudica & 25,8 & 28,8 & 26,2 & 28,0 & 28,7 & 30,7 & 40,2 & 30,1 \\
No afecta & 29,3 & 30,2 & 33,1 & 27,4 & 31,1 & 32,8 & 24,9 & 28,6 \\
NS/NR & 14,6 & 10,9 & 11,5 & 12,7 & 9,4 & 10,1 & 7,7 & 9,2 \\
ÍNDICE* & $+4,6$ & $+1,3$ & $+3,1$ & $+3,8$ & $+2,1$ & $-4,2$ & $-13,0$ & $+2,0$ \\
\hline
\end{tabular}

$*$ Índice $=\%$ Beneficia $-\%$ Perjudica.

Fuente: PROCESOS, Encuestas TLC mayo-octubre, 2007.

La población tendió a dividirse en tercios sobre si el TLC les beneficiaba, les perjudicaba 0 les era indiferente. Sin embargo, en las últimas dos mediciones de setiembre se rompe este patrón, cuando el grupo que se veía perjudicado llegó al 40\% de la población. Ello se observa en forma aún más pronunciada en el siguiente gráfico que presenta el índice de beneficia menos perjudica.

\section{GRÁFICO 13}

EVOLUCIÓN DEL ÍNDICE DEL EFECTO DEL TLC SOBRE LA PERSONA O SU FAMILIA MAYO-OCTUBRE 2007

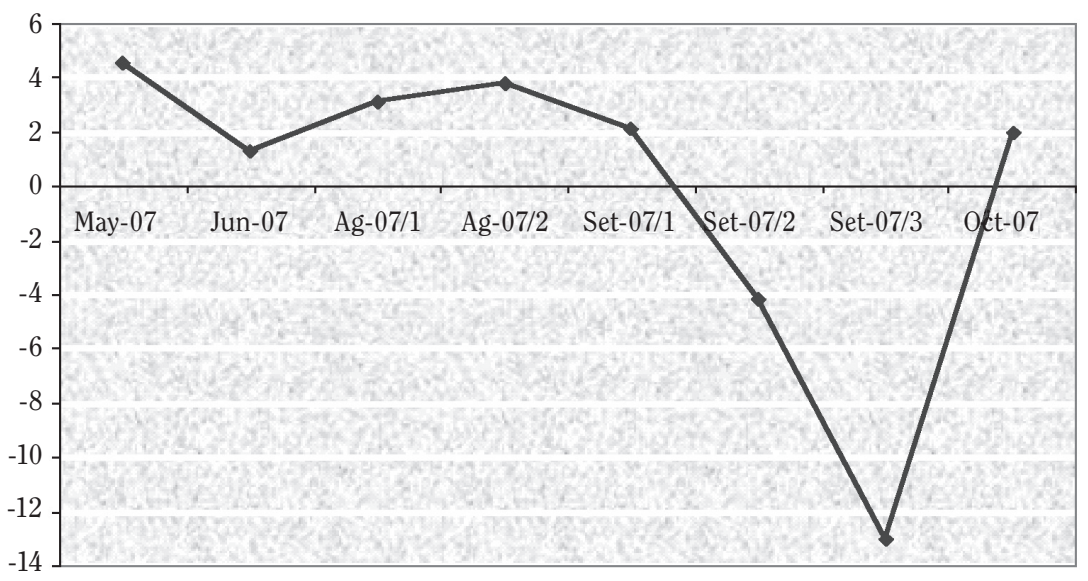

Fuente: PROCESOS. Encuestas TLC mayo-octubre, 2007. 


\section{PARTE D: COMENTARIOS FINALES}

El trabajo de seguimiento permite observar que la población se planteó los principales temas que se argumentaron a favor del sí y a favor del No. El debate reflejó un país solidario e innovador que juzgaba los argumentos mediante ese lente. Resaltaron así como polos la promesa de creación del empleo versus los posibles efectos negativos sobre los grupos más vulnerables de la sociedad. La mayor parte de la población opinó durante todo el período estudiado que el TLC no beneficiaría a las personas pobres $y$ sin estudios (entre 67,8\% y 54,7\%), ni a los pequeños agricultores (entre 59\% y 49\%). Al mismo tiempo, la mayoría también opinaba que sería una fuente de empleo (entre 55\% y 62\%). Ponderar en la balanza estos dos extremos fue uno de los ejes principales entre los cuales se debatió la opinión pública costarricense.

Tres elementos adicionales afectaron a la población: el papel de Estados Unidos como país restrictivo de nuestra soberanía, el desarrollo del Estado Solidario y el efecto percibido sobre las personas individuales.

Pese a la historia costarricense de apoyo hacia los Estados Unidos, la campaña del TLC se dio en una coyuntura de crítica hacia ese país, especialmente por la guerra. La paz es un elemento constitutivo de la concepción democrática tica. También influyó en el clima de temor, la desproporción de poderío entre ambos países. La percepción de que con el Tratado Estados Unidos lograría mayor influencia en el país dominó a la mayoría de las personas costarricenses (62\%).

La apreciación del impacto del TLC sobre el Estado Solidario, fue más inestable y en ese sentido se puede afirmar que fue más impactado por el debate. El tema es de gran relevancia en el dilema empleo-grupos pobres, pues se espera que el Estado brinde protección a los grupos vulnerables. El índice sobre la opinión acerca de la no privatización del ICE, presenta una tendencia que va desde valores negativos hasta los positivos (-14,1\% hasta 7,6\%). El índice de las opiniones sobre la posible quiebra de la cCSS y la reducción de servicios de salud y educación se mantuvieron en los valores positivos todo el período, pero con inestabilidad.
Finalmente, se puede hacer una observación que refuerza lo dicho al inicio de estos comentarios, en el sentido de que la perspectiva solidaria e innovadora permeó la toma de decisión sobre el voto. Tuvo más relevancia la preocupación por el país que por los grupos vulnerables que el impacto percibido del TLC sobre la persona entrevistada. Esta no tuvo grandes fluctuaciones y se mantuvo durante la campaña aproximadamente en tercios entre beneficiados, perjudicados e indiferentes.

El reto mayor en el uso del Referéndum es la capacidad de dar información sencilla, veraz y balanceada. En esta ocasión el electorado no quedó satisfecho y al final sufrió de gran indecisión por esta misma razón. El financiamiento estatal puede ser un pivote necesario para enfrentar este reto.

\section{BIBLIOGRAFÍA}

Drummond, Andrew J. "Electoral Volatility and Party Decline in Western Democracies: 1970-1995”. Political Studies 54 (3), octubre. 2006.

Pecóu Daley, Diorssette. El Referéndum en Costa Rica. Asamblea Legislativa de Costa Rica. Centro de Investigación Legislativa (CEDIL). Dossier Nro. 37-2007. En: <http://www.asamblea.go.cr/biblio/ cedil/index.htm>. San José, Costa Rica. 2007.

Rodríguez, Florisabel; Espinosa y Madrigal. "El final del bipartidismo en Costa Rica: un retrato electoral 1994-2002". Revista de Ciencias Sociales 109-110. Universidad de Costa Rica, 2005.

Rodríguez, Florisabel; Castro, S. "Partidos y Asamblea: representación en crisis". Revista Parlamentaria 7 (2), agosto. 1999: 285-305.

Ser Huan Poon. A Practical Guide to Forcasting Market Volatility. New York: Wiley Finance Series, 2005. 
Sobrado González, Luis Antonio. "Primera experiencia de referéndum en Costa Rica: regulación y alcances". Revista Digital de Derecho Electoral 4. Segundo Semestre. Tribunal Supremo de Elecciones. En: $<$ http://www.tse.go.cr/revista/revista. htm> San José, Costa Rica. 2007.
Tribunal Supremo de Elecciones. Resultado oficial Referéndum. 2007. En: <www.tse. go.cr> 
